\section{Factors influencing breath condensate volume}

\begin{abstract}
Analysis of breath condensate (BC) has received interest recently due to the need for easy and repetitive monitoring of airway and pulmonary disease. While many authors have used custom built systems, commercial systems are now available and will probably be used more widely. Early studies of markers and mediators in BC have reported concentrations following varying periods of sampling time. However, factors that influence the generation of BC have not been analysed and it is unclear whether breathing rate, tidal volume, lung function, body weight, height or age influence the amount of BC collected. We therefore studied the influence of these factors on breath condensate volume and breath condensate urea and protein concentrations in 22 healthy volunteers and 23 COPD patients.
\end{abstract}

A strong correlation of total respired volume and breath condensate volume was observed for both groups (volunteers: $r=0.952, p<0.0001$, COPD: $r=0.883, p<0.0001$ ) while no significant correlation existed for breath condensate volume and TLC, RV, VC, FEV1, $R_{\text {tot }}$, height or body weight. As long as ventilation remained fairly constant, breath condensate volume increased linearly with time. The fraction of breath condensate extracted from total vapour contained in the exhalate was estimated by measuring relative atmospheric humidity before and after the collecting tube. The amount calculated by the change in temperature and saturation corresponded closely to the amount actually collected.

We conclude from these results that breath condensate volume is primarily dependent on $V_{E}$, and does not seem to depend on lung function parameters. For standardisation it is suggested to report breath condensate measurements per volume respired. Both, urea and protein are present in measurable quantities in breath condensate and protein as well as BCV may be helpful denominators for comparison with e.g. cytokines in lung disease.

\section{Introduction}

Breath condensate has been suggested to be a non-invasive method of sampling the epithelial lining fluid (ELF) or more precisely that part of the ELF that finds its way into the

Pneumologie 2001; 55: 414-419

(c) Georg Thieme Verlag Stuttgart · New York ISSN 0934-8387
C. Gessner, H. Kuhn, H.-J. Seyfarth, H. Pankau, J. Winkler, J. Schauer, H. Wirtz

Medizinische Klinik und Poliklinik I, Universitätsklinikum Leipzig

exhalate. Regardless whether it truly reflects ELF, breath condensate contains not only soluble small molecules and hydrogen peroxide [3], but also a number of large molecules such as leukotrienes B4, C4, D4, E4, Prostaglandin E2 ECP, IL-1 sIL-2R, TNF-, isoprostane, tumour markers and small amounts of DNA $[1,4-7,15]$. BC evaluation may be helpful in determining the degree of airway inflammation or epithelial damage, investigating surfactant integrity, tumour growth and possibly genome mutations $[4,5]$. Breath condensate has been used for analysis of leukotrienes in inflammatory upper airway disease [8], $\mathrm{H}_{2} \mathrm{O}_{2}$ and $\mathrm{pH}$ in asthma [2,9], several markers of inflammation in COPD [10,11], and mechanically ventilated patients, patients with acute respiratory failure $[12,13]$ and cigarette smokers [14]. In addition to the variety of parameters that may be monitored in breath condensate it's attractiveness is the ease of sample collection. This allows frequent follow up and improved control of lung disease when appropriate markers have been identified. In addition breath condensate monitoring is less expensive than more invasive ways of monitoring lung disease.

Most likely, breath condensate is a mixture of water vapour and aerosolised ELF, but the exact origin and mechanism of breath condensate generation remains to be determined. Collection of this material involves rapid cooling of the exhalate with condensation of water vapour as well as sedation and attachment of aerosol particles to very cold surfaces. The relative importance of extraction by cooling (condensate formation) and sedation due to gravity or impact for the process of condensate formation has been debated. Complete extraction from the exhalate to a freezing cold surface will depend on the size and shape of the surface, the velocity of the airstream passing the cold surface and the temperature gradient [8].

For the future it will be useful to define factors influencing breath condensate formation and ways for standardization of breath condensate collection. Without sufficient knowledge of influential parameters, breath condensate collection will suffer from many of the drawbacks of examining solutes in bronchoalveolar lavage fluid [16].

We here investigated the influence of ventilation $\left(\mathrm{V}_{\mathrm{E}}\right)$ and lung function as well as individual parameters on breath condensate volume. In addition we examined the effectiveness of breath condensate collection by determining humidity and temperature in the exhalate before and after the cold trap. 


\section{Material and methods}

Breath condensate was collected using the ECoSreen ${ }^{\circledR}$ (Jaeger/ Toennies, Wuerzburg, Germany). This device has a cold trap with one collecting tube (Ct-1) inserted into a receptacle integrated into the cooled head sampling unit. A second cold trap was fitted to the exhalation port of the first one: This second trap called collecting tube II (Ct-2) was cooled to $-20^{\circ} \mathrm{C}$ by immersion into dry ice in ethanol. The outlet of this second cold trap was open to the surrounding (Fig. 1).

Breath condensate was collected during three consecutive 10 min periods. "Normal breathing" was requested by the unit operator, but intentionally no influence on rate or tidal volume was exerted. For each of the 10 min periods, aliquots were stored separately after briefly thawing and collecting the entire fluid into the detachable part of the collecting tube. For each of the three collection periods the tube in Ct-1 position was exchanged, while in the $\mathrm{Ct}-2$ position only one collection tube was used for the entire time sampling period of $30 \mathrm{~min}$. In total four different aliquots were therefore collected from each individual.

Measurement of $\mathrm{V}_{\mathrm{E}}$ was performed with a bellows type gas flow counter (Model BK4, Krom Schröder, Germany: $Q_{\min }$ : $0.04 \mathrm{~L} / \mathrm{min}, \mathrm{Q}_{\max }: 6.0 \mathrm{~L} / \mathrm{min}$; accuracy $\pm 1.5 \%$ at $20^{\circ} \mathrm{C}$ ) fitted to the inspiratory opening. 22 healthy volunteers and 23 patients with a COPD underwent a complete lung function study.

Humidity was measured using a precision hygrometer (P 570; Novodirect, Germany; sensor precision $1 \%$ for humidity, $1{ }^{\circ} \mathrm{C}$ for temperature, sensor resolution $0.1 \%$ for humidity, $0.1^{\circ} \mathrm{C}$ for temperature) with a minimum registration interval of $1 \mathrm{~s}$. Smartgraph 1.07 and De Terminal P 500 software was used for evaluation (Dostmann electronic GmbH, Wertheim, Germany).

Relative humidity and temperature were measured at the inand outlet of the collecting tube consecutively. $V_{E}$ was calculated from $V_{I}$ measured at the inspiratory port using the equation: $\mathrm{V} 1 / \mathrm{T} 1=\mathrm{V} 2 / \mathrm{T} 2$. The amount of water in the air entering and leaving the collecting tube was calculated [17] and plotted versus time (100 s; $n=8$ volunteers; example in Fig. 2). The area under the resulting curve (AUC) thus represented the amount of water that had entered/left the collecting tube. The calculated difference represented the extracted fraction. The extracted fraction was then compared to the amount actually collected. The difference between these two was interpreted to be due to incomplete yield from the cold trap after the process of thawing and pipetting.

Protein concentration contained in breath condensate was measured using the Micro BCA Protein Assay (Pierce, Rockford USA) with a linear working range of $0.5-20 \mu \mathrm{g} / \mathrm{ml}[18,19]$. For the reason of comparison, samples from Ct-1 and Ct-2 were analysed separately.

In order to exclude a possible contamination of breath condensate by saliva we measured amylase activity in breath condensate of all volunteers and patients. As a reference value for amylase activity in saliva we used the average saliva value of five volunteers. Amylase activity was determined with the alpha-Amylase ESP 1491300 kit (test limit $0.03 \mu \mathrm{mol} / \mathrm{l}^{*} \mathrm{~s}$;

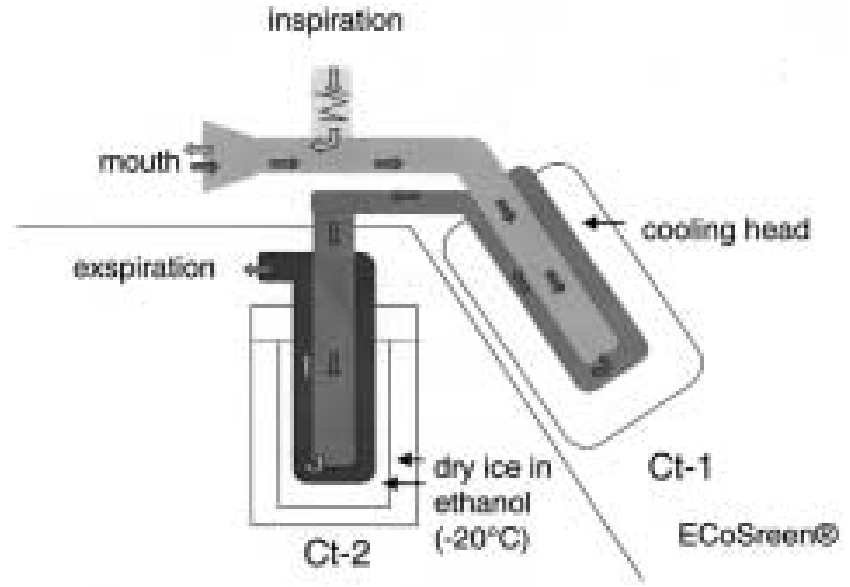

Fig. 1 Schematic drawing of the breath condensate collection device $\left(\right.$ EcoScreen $\left.^{\circledR}\right)$.

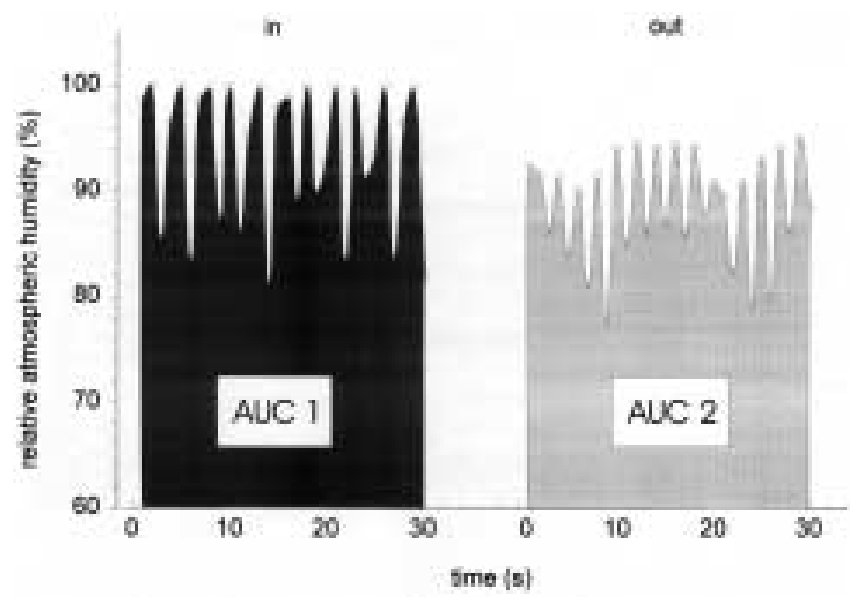

Fig. 2 Relative atmospheric humidity vs. time. On-line registration of relative atmospheric humidity (minimum interval one second). Air entering (in) and exiting (out) the collecting tube is shown over a time period of $30 \mathrm{~s}$. For statistic evaluation, the area under the curve (AUC) was compared.

Boehringer Mannheim, Germany). For quantitative determination of urea nitrogen in breath condensate we used a BUN test kit from Sigma (Deisenhofen, Germany).

Statistical analysis was performed with the SPSS software package (SPSS Inc., Chicago, USA). Linear regression analysis was used for analysing the influence of $V_{E}$ and lung function variables on breath condensate volume from each of the three sampling periods. Inter-individual as well as intra-individual comparisons of condensate volumes from all the sampling periods were performed by ANOVA testing. $\mathrm{p}$ was considered significant at the $5 \%$ level. Results are mean \pm SD.

\section{Results}

Breath condensate volumes and ventilation of volunteers and COPD patients are listed in Table 1. $\mathrm{V}_{\mathrm{E}}$ ranged from $37-302 \mathrm{~L}$ in the volunteer group and from $27-238 \mathrm{~L}$ in the COPD group (all $10 \mathrm{~min}$ periods included). We observed no significant variation of $V_{E}$ within individuals comparing the first, second 
Table $1 \quad B C V$ and $V_{E}$ in COPD and volunteers

\begin{tabular}{lllllll}
\hline Sampling period & $\begin{array}{l}\text { BCV } \\
\text { volunteers }\end{array}$ & COPD & $P$ & \multicolumn{1}{c}{$\begin{array}{l}V_{E} \\
\text { volunteers }\end{array}$} & COPD & P \\
\hline $0-10 \mathrm{~min}$ & $0.94 \mathrm{ml} \pm 0.53$ & $1.22 \mathrm{ml} \pm 0.57$ & 0.10 & $102.6 \mathrm{~L} \pm 53.3$ & $129.5 \mathrm{~L} \pm 62.1$ \\
$11-20 \mathrm{~min}$ & $0.93 \mathrm{ml} \pm 0.43$ & $0.98 \mathrm{ml} \pm 0.54$ & 0.71 & $96.4 \mathrm{~L} \pm 43.4$ & $105.4 \mathrm{~L} \pm 58.2$ & 0.58 \\
$21-30 \mathrm{~min}$ & $0.97 \mathrm{ml} \pm 0.54$ & $1.13 \mathrm{ml} \pm 0.47$ & 0.49 & $102.4 \mathrm{~L} \pm 59.3$ & $120.7 \mathrm{~L} \pm 59.6$ & 0.48 \\
average & $0.94 \mathrm{ml} \pm 0.49$ & $1.12 \mathrm{ml} \pm 0.55$ & 0.09 & $100.5 \mathrm{~L} \pm 51.8$ & $118.9 \mathrm{~L} \pm 60.1$ & 0.08 \\
\hline
\end{tabular}

Date shown as mean \pm SD

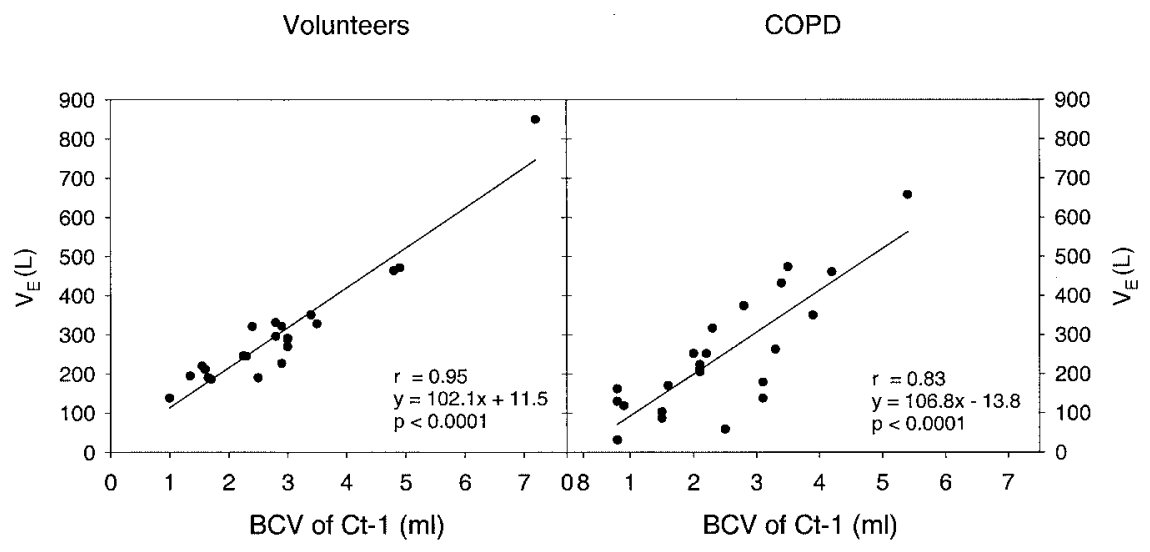

Fig. 3 Correlation of $B C V$ and $V_{E}$. Breath condensate volume in the first trap $(\mathrm{Ct}-1)$ increased linearly with $\mathrm{V}_{\mathrm{E}}$ in volunteers $(y=102.1 x+11.5 ; r=0.952 ; p<0.0001)$ and COPD patients $(y=110.2 x-8.8 ; r=0.883$; $\mathrm{p}<0.0001)$. and third 10 min periods (data not shown) and there was also no significant within-subject variability of BCV (mean \pm SD in volunteers: $0.95 \mathrm{ml} \pm 0.14, \mathrm{p}=0.96$; mean $\pm \mathrm{SD}$ in COPD patients: $1.18 \mathrm{ml} \pm 0.15, \mathrm{p}=0.38$ ).

The correlation of BCV and $\mathrm{V}_{\mathrm{E}}$ in the first cold trap (Ct-1) for the entire $30 \mathrm{~min}$ sampling period for volunteers and COPD patients is shown in Fig. 3. Correlation of BCV and $V_{E}$ for the second cold trap (Ct-2) was also very strong for volunteers $(\mathrm{y}=75.3 \mathrm{x}+44.4, \mathrm{r}=0.95, \mathrm{p}<0.0001)$ as well as for COPD patients $(\mathrm{y}=91.0 \mathrm{x}+72.9, \mathrm{r}=0.87, \mathrm{p}<0.0001)$. Comparably strong correlations were observed when each of the $10 \mathrm{~min}$ periods was analysed separately (volunteers: first $10 \mathrm{~min}$ period: $r=0.91, p<0.0001$, second 10 min period: $r=0.90$, $\mathrm{p}<0.0001$, third 10 min period: $\mathrm{r}=0.92, \mathrm{p}<0.0001$; COPD patients: 0 - 10 min: $r=0.75, p<0.0001,10-20 \mathrm{~min}$ : $\mathrm{r}=0.83, \mathrm{p}<0.0001,20-30 \mathrm{~min}: \mathrm{r}=0.94, \mathrm{p}<0.001)$. The increase of BCV as well as the increase of $V_{E}$ with time was parallel. Table 1 shows BCV and $\mathrm{V}_{\mathrm{E}}$ in volunteers and COPD patients. The ratio of $\mathrm{V}_{\mathrm{E}} / \mathrm{BCV}$ was almost identical in both groups (data not shown). COPD patients exhibited an increased, compensatory ventilation leading to a concomitant increase in BCV.

$A V_{E}$ of $100 \mathrm{~L}$ resulted in a BCV of $0.95 \mathrm{ml} \pm 0.24$ in volunteers and $1.02 \mathrm{ml} \pm 0.39$ in COPD patients. The relation of $V_{E} / B C V$ did not vary significantly in the three sampling periods.

None of the lung function parameters measured (TLC, VC, RV, FEV1 and $R_{\text {tot }}$ ) correlated significantly with BCV in either volunteers or COPD patients (table 2 ). Age and bodyweight were not significantly influential on breath condensate volume (Table 2).
The efficiency of breath condensate collection was evaluated in eight consecutive volunteers. In these individuals mean temperature and relative humidity at the inlet of $\mathrm{Ct}-1$ was $29{ }^{\circ} \mathrm{C} \pm 0.41$ and $88.05 \% \pm 4.44$ respectively. The corresponding mean values at the outlet of $\mathrm{Ct}-1$ were $19^{\circ} \mathrm{C} \pm 0.5$ and $83.99 \%$ \pm 3.5 (Fig. 4).

The percentage of water extracted from breath condensate by Ct- 1 was $36.9 \% \pm 6.1$ in volunteers and $40.7 \% \pm 14.9$ in COPD patients. Comparably the second cold trap in a row extracted $43.7 \% \pm 7.8$ in volunteers and $30.2 \% \pm 11.5$ in COPD patients. All together with both traps $80.6 \% \pm 10.5$ was extracted in volunteers and $70.9 \% \pm 17.2$ in COPD patients. Thus no difference existed in the efficiency of water vapour extraction in healthy individuals versus COPD patients.

Mean protein concentrations in all breath condensate aliquots were $11.9 \mu \mathrm{g} / \mathrm{ml} \pm 8.9$ in volunteers and $12.9 \mu \mathrm{g} / \mathrm{ml} \pm 7.6$ in COPD patients. Concentrations in aliquots of $\mathrm{Ct}-1$ were similar to those of Ct-2 (volunteers: Ct-1 $10.6 \mu \mathrm{g} / \mathrm{ml} \pm 6.2$ vs. Ct-2 $13.3 \mu \mathrm{g} / \mathrm{ml} \pm 10.9 ; \mathrm{p}=0.32$; COPD patients: Ct-1 $13.5 \mu \mathrm{g} / \mathrm{ml}$ \pm 9.3 vs. Ct- $212.4 \mu \mathrm{g} / \mathrm{ml} \pm 5.5, \mathrm{p}=0.62$ ). Total protein correlated significantly with $\mathrm{BCV}$ (volunteers: $\mathrm{r}=0.78, \mathrm{p}<0.0001$; COPD patients: $\mathrm{r}=0.46 ; \mathrm{p}=0.027$ ) as well as $\mathrm{V}_{\mathrm{E}}$ (volunteers: $r=0.65, p<0.001$; COPD patients: $r=0.49, p=0.017$; Fig. 5A). Because $B C V$ and $V_{E}$ both were strongly correlated with protein concentration, our findings suggest that protein accumulated by a similar mechanism as breath condensate. The weaker correlation in COPD patients may indicate additional or reduced mechanisms of protein entering the cold trap in COPD patients. 


\begin{tabular}{lllll}
\hline parameters & \multicolumn{2}{l}{$\begin{array}{l}\text { volunteers } \\
\text { (collecting unit 1) }\end{array}$} & \multicolumn{2}{l}{$\begin{array}{l}\text { COPD patients } \\
\text { (collecting unit 1) }\end{array}$} \\
& $\mathrm{R}$ & $\mathrm{P}$ & $\mathrm{R}$ & $\mathrm{P}$ \\
\hline age [year] & 0.31 & 0.16 & 0.19 & 0.38 \\
bodyweight $[\mathrm{kg}]$ & 0.37 & 0.09 & 0.02 & 0.92 \\
height [cm] & 0.20 & 0.37 & 0.12 & 0.58 \\
TLC & 0.28 & 0.20 & 0.06 & 0.78 \\
VC $^{* *}$ & 0.24 & 0.29 & 0.16 & 0.46 \\
RV*** & 0.32 & 0.14 & 0.08 & 0.72 \\
FEV1\#\# & 0.04 & 0.87 & 0.16 & 0.46 \\
R tot\# & 0.18 & 0.41 & 0.17 & 0.45 \\
volume respired [L] & 0.96 & 0.0001 & 0.88 & 0.0001 \\
\hline
\end{tabular}

Table 2 Correlation of biological and lung function parameters with breath condensate volume.

* total lung capacity [L]; ** vital capacity [L]; ${ }^{* * *}$ residual volume [L]; \#\# forced expiratory volume [L]

\# airway resistance $[\mathrm{kPa} * \mathrm{~s} / \mathrm{L}]$

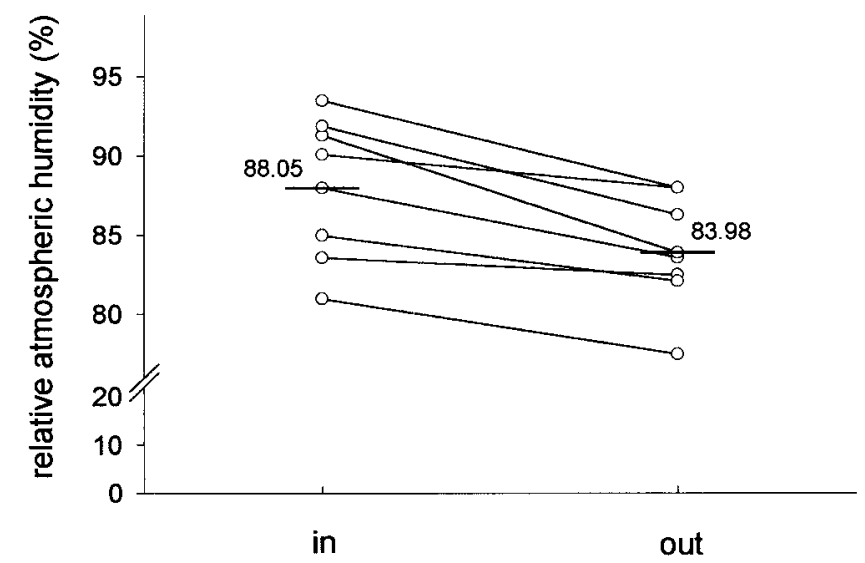

Fig. 4 Relative atmospheric humidity entering and exiting the cold trap. Relative atmospheric humidity determined in a group of eight volunteers. Humidity as measured at the inlet (in) and outlet (out) of the cold trap for each individual.

Activity of alpha-amylase was undetectable in BCV of volunteers or COPD patients. The reference value of alpha-amylase activity in saliva (measured in five volunteers) was $7.3 \mu \mathrm{mol} /$ $1^{*} \mathrm{~s} \pm 4.9$.

Measurement of urea concentration was performed in breath condensate from Ct-1 as well as Ct-2. Mean urea concentration was significantly elevated in COPD patients $(370.4 \mu \mathrm{mol} / \mathrm{l}$ \pm 244.21 ) compared to healthy volunteers (83.6 $\mu \mathrm{mol} / \mathrm{l}$ \pm 56.3 ). Correlating the absolute amount of urea with BCV and $V_{E}$ we observed a linear regression for urea and $B C V(r=0.91$; $\mathrm{p}<0.0001)$ as well as for urea and $\mathrm{V}_{\mathrm{E}}(\mathrm{r}=0.92 ; \mathrm{p}<0.0001$; Fig. 5B) in volunteers only.

\section{Discussion}

In this study of 22 healthy volunteers and 23 COPD patients we have demonstrated that breath condensate volume depends primarily on ventilation. Lung function, body weight, height, and age did not correlate significantly with the amount of breath condensate recovered. A correlation of BCV with ventilation might have been expected, however we did not foresee the lack of other influential factors in these two populations of healthy individuals and COPD patients. In addition, the correlation of BCV and ventilation is extraordinarily strong and leaves little room for other influential factors.

Although it may seem of minor importance that BCV is predominantly dependent on ventilation, this finding will facilitate breath condensate evaluation to a great extent. Inter- or even intra-individual variability in the amount of breath condensate volume in relation to ventilation would have suggested different mechanisms of breath condensate generation with varying relative importance. For example the role of aerosol admixture to aqueous vapour could have been greatly variable. This in turn would have suggested a varying composition of the condensate and a need for a close control of ventilation parameters. However with a linear and strong correlation of breath condensate volume in healthy volunteers with ventilation over a rather wide range it is unlikely that mechanisms of breath condensate generation differ significantly depending on physiological differences in lung function, body size, weight and age. Further support of this interpretation comes from the linear correlation of ventilation with total protein in breath condensate. This was true for volunteers as well as for COPD patients although correlation was not as good in the latter group. Alternative, additional or reduced mechanisms of protein entering the cold trap may therefore exist in COPD.

Reinhold et al. have also described a correlation of ventilation (minute volume) and breath condensate volume (per minute) in calves. However, these authors demonstrated a dependency of breath condensate volume on body weight and tidal volume [20]. In our study, lung function parameters were of no significant influence in determining breath condensate volume.

We did not control for a difference in tidal volume in this study in order to avoid any influence on ventilation. Nevertheless, it is suggested from our data that the wide range of volumes ventilated in the 10 min periods $(37-307 \mathrm{~L} / \mathrm{min}$ in volunteers and $27-238 \mathrm{~L} / \mathrm{min}$ in COPD) is not merely due to differences in breathing frequency but also involves a range of tidal volumes and nevertheless results in close correlation of 

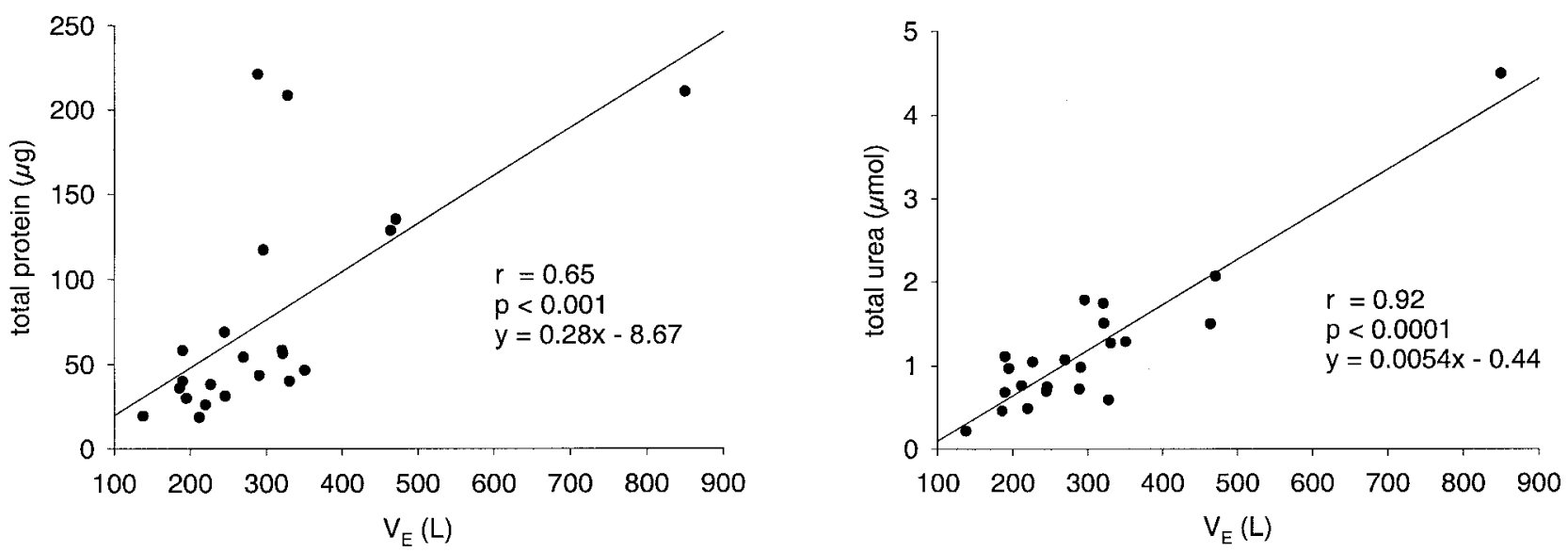

Fig. 5 Total protein and urea versus VE. A Linear correlation of total protein with VE (B; $r=0.65, p<0.001, y=0.28 x-8.67)$. B Linear correlation of total urea with VE $(B ; r=0.92, p<0.0001, y=0.0054 x-0.44)$.

$\mathrm{BCV}$ and $\mathrm{V}_{\mathrm{E}}$. The usefulness of breath condensate collection will be greater if tidal volume needs not to be tightly controlled. Our findings do not implicate that tidal volume is a critical factor for neither breath condensate volume nor the constituents protein and urea measured in this study.

The small intra-individual variation in the relation of BCV and $V_{E}$ and the close correlation of protein with either BCV or $V_{E}$ suggest that solutes in BCV will also vary only very little within a given healthy subject. In fact, little intra-individual variation between the three collection periods with respect to urea and protein concentration was observed in this series of measurements. Therefore collection of breath condensate is unlikely to be a mechanism that is easily exhausted or altered during the process of breath condensate collection but instead appears to be extendable by increasing the collection period or repetitive collection if more material is needed. We exchanged collecting tubes at $10 \mathrm{~min}$ intervals. The capacity of the tubes used in the ECoScreen ${ }^{\circledR}$ appears to be adequate for a thirty minute collection period as was demonstrated by Ct-2 in this study which was removed following a $30 \mathrm{~min}$ period instead of 10 and still showed a similar effectiveness in terms of extraction when compared to $\mathrm{Ct}-1$.

In contrast to $\mathrm{BCV} \mathrm{V}_{\mathrm{E}}$ showed considerable variation as mentioned above. All individuals were asked to breath normally into the mouthpiece of the collection device. Frequently we observed initial short periods of hyperventilation. However five individuals were moderately (432 L, $461 \mathrm{~L}$, 464 L, 471 L, 474 L) and two were markedly (658 L, 850 L) hyperventilating during breath condensate collection. We have intentionally made no effort to influence breathing of volunteers during the collection period in order to test the hypothesis of the linear correlation of ventilation and BCV.

The average volume of breath condensate collected by Ct-1 in our study was $0.95 \mathrm{ml}$ for every $100 \mathrm{~L}$ of $\mathrm{V}_{\mathrm{E}}$ in healthy volunteers and $1.02 \mathrm{ml}$ for COPD patients. This is slightly below $50 \%$ of the entire amount of water in the exhalate calculated from temperature and saturation. When both collecting tubes had been installed in a serial array effectiveness almost doubled. This might be expected since the area for condensation doubled and temperature was very comparable $\left(-20^{\circ} \mathrm{C}\right)$ in both collecting tubes. However, this demonstrates that in addition to increasing $\mathrm{V}_{\mathrm{E}}, \mathrm{BCV}$ can also be increased by increasing the surface area for condensation even if this means a serial set up. Breath condensate volumes collected from a single trap were similar to the volume collected in $200 \mathrm{~cm}$ tubing connected to the expiratory port of a ventilator and running through saline-ice water collecting condensate from mechanically ventilated patients in another study [13].

The relative atmospheric humidity of $88 \%$ at the mouthpiece instead of the theoretical humidity of $100 \%$ (i.e. BTPS conditions) suggests a dilution of expired gas with air from the nasopharynx. During the passage through the first cold trap humidity fell to an average of $84 \%$. This may not seem to be a large difference, however considering the drop in temperature from 29 to $19{ }^{\circ} \mathrm{C}$ this relates to a considerable loss of water by condensate formation.

BCV actually collected was approximately $80 \%$ of the amount of condensate extracted from the exhalate according to the measurements of humidity and temperature. The residual difference may partially be explained by the loss of small amounts of fluid during recovery from the cold trap ( $\mathrm{Ct}-1, \mathrm{Ct}-2)$ when the frozen condensate has to be thawed and transferred into vials for further processing. The close correspondence of volume extracted and volume actually recovered with some allowance for unrecovered volume also lends support to the interpretation that condensation due to a drop in temperature is in fact the relevant mechanism of breath condensate generation. The alternative possibility of impact driven condensate deposition does not appear to be an important 
mechanism at least with respect to BCV. If this was untrue, a difference in the ventilation/volume ratio of the first cold trap versus the second cold trap would have been expected, since an impact driven condensate formation would be expected to prefer the first trap.

Protein and urea were both detectable with standard assays in breath condensate. The total amount of protein increased with $B C V$ as well as $V_{E}$ for both groups. For urea this was only true for volunteers, most likely reflecting differences in kidney function of COPD patients. Protein may therefore be a useful denominator for other ELF ingredients e.g. inflammatory mediators.

In conclusion, breath condensate volume is mainly dependent on ventilation, and when corrected for ventilation, is very constant in healthy volunteers as well as in COPD patients. Thus breath condensate volume should be reported with regard to expired volume (rather than time). These observations may help in the interpretation of breath condensate studies and in designing new studies using this indubitably useful tool of pulmonary medicine. As demonstrated here with protein and urea breath condensate contains ingredients most likely derived from the epithelial lining fluid of the lung parenchyma and/or the airways. These ingredients appear to increase linearly with ventilation in healthy individuals and do so albeit more loosely correlated in COPD patients which suggests that analyses requiring larger amounts of material will be feasible by increasing ventilation or collecting repetitively.

\section{Acknowledgements}

This work was partially funded by a research grant from the „Deutsche Atemwegsliga“.

\section{References}

${ }^{1}$ Montuschi P, Kharitonov SA, Ciabattoni G, Corradi M, van Rensen L, Geddes DM, Hodson ME, Barnes PJ. Exhaled 8-isoprostane as a new non-invasive biomarker of oxidative stress in cystic fibrosis. Thorax 2000; 55 (3): 205-209

${ }^{2}$ Hunt JF, Fang K, Malik R, Snyder A, Malhotra N, Platts-Mills TA, Gaston B. Endogenous airway acidification. Implications for asthma pathophysiology. Am J Respir Crit Care Med 2000; 161 (3 Pt 1): 694-699

${ }^{3}$ Loukides S, Horvath I, Wodehouse T, Cole PJ, Barnes PJ. Elevated levels of expired breath hydrogen peroxide in bronchiectasis. Am J Respir Crit Care Med 1998; 158 (3): 991 - 994

${ }^{4}$ Gessner C, Seyfarth HJ, Hoheisel G, Winkler J, Hillebrand T, Schauer J. Identification of K-ras gene mutations in breathing condensate of patients with non small cell lung cancer (NSCLC) as a non-invasive method for screening (abstract). Am J Respir Crit Care Med 1998; 157: A693

${ }^{5}$ Gessner C. Detection of mutations of the K-ras gene in condensed breath of patients with non-small-cell lung carcinoma (NSCLC) as a possible noninvasive screening method. Pneumologie 1998; 52(7): 426-427

${ }^{6}$ Hillebrand T, Bendzko P, Beck E, Becher G, Roth M, Neubauer G, Norpoth K, Stresemann E. Isolation of DNA from breathing condensate (abstract). Am J Respir Crit Care Med 1996; 153: A181

${ }^{7}$ Montuschi P, Corradi M, Ciabattoni G, Nightingale J, Kharitonov SA, Barnes PJ. Increased 8-isoprostane, a marker of oxidative stress, in exhaled condensate of asthma patients. Am J Respir Crit Care Med 1999; 160 (1): 216-220

${ }^{8}$ Becher G, Winsel K, Beck E, Neubauer G, Stresemann E. Breath condensate as a method of noninvasive assessment of inflammation mediators from the lower airways. Pneumologie 1997; 51 (Supp 2): 456-459

${ }^{9}$ Antczak A, Nowak D, Bialasiewicz P, Kasielski M. Hydrogen peroxide in expired air condensate correlates positively with early steps of peripheral neutrophil activation in asthmatic patients. Arch Immunol Ther Exp (Warsz) 1999; 47(2): 119-126

${ }^{10}$ Dekhuijzen PN, Aben KK, Dekker I, Aarts LP, Wielders PL, van Herwaarden CL, Bast A. Increased exhalation of hydrogen peroxide in patients with stable and unstable chronic obstructive pulmonary disease. Am J Respir Crit Care Med 1996; 154 (3 Pt 1): $813-816$

${ }^{11}$ Horvath I, Loukides S, Wodehouse T, Kharitonov SA, Cole PJ, Barnes PJ. Increased levels of exhaled carbon monoxide in bronchiectasis: a new marker of oxidative stress. Thorax 1998; 53 (10): $867-870$

12 Kietzmann D, Kahl R, Muller M, Burchardi H, Kettler D. Hydrogen peroxide in expired breath condensate of patients with acute respiratory failure and with ARDS. Intensive Care Med 1993; 19 (2): $78-81$

${ }^{13}$ Sznajder JI, Fraiman A, Hall JB, Sanders W, Schmidt G, Crawford G, Nahum A, Factor P, Wood LD. Increased hydrogen peroxide in the expired breath of patients with acute hypoxemic respiratory failure. Chest 1989; 96 (3): 606-612

${ }^{14}$ Nowak D, Antczak A, Krol M, Pietras T, Shariati B, Bialasiewicz P, Jeczkowski K, Kula P. Increased content of hydrogen peroxide in the expired breath of cigarette smokers. Eur Respir J 1996; 9 (4): $652-657$

${ }^{15}$ Scheideler L, Manke HG, Schwulera U, Inacker O, Hammerle H. Detection of nonvolatile macromolecules in breath. A possible diagnostic tool? Am Rev Respir Dis 1993; 148 (3): 778- 784

${ }^{16}$ Haslam PL, Baughman RP. Report of ERS Task Force: Guidelines for measurement of acellular components and standardization of BAL [editorial]. Eur Respir J 1999; 14 (2): 245-248

${ }^{17}$ von Vogel HU. Chemiker-Kalender, 1th ed. Springer-Verlag, Berlin, Göttingen,Heidelberg, 1956

${ }^{18}$ Smith PK, Krohn RI, Hermanson GT, Mallia AK, Gartner FH, Provenzano MD, Fujimoto EK, Goeke NM, Olson BJ, Klenk DC. Measurement of protein using bicinchoninic acid. Anal Biochem $1985 ; 150$ (1): $76-85$

${ }^{19}$ Wiechelman KJ, Braun RD, Fitzpatrick JD. Investigation of the bicinchoninic acid protein assay: identification of the groups responsible for color formation. Anal Biochem 1988; 175 (1): 231- 237

${ }^{20}$ Reinhold P, Langenberg A, Becher G, Rothe M. Breath condensate - a medium obtained by a noninvasive method for the detection of inflammation mediators of the lung. Berl Munch Tierarztl Wschr 1999; 112 (6-7): $254-259$

\section{Dr. Christian Gessner}

Medizinische Klinik und Poliklinik I

Universitätsklinikum Leipzig

Johannisallee 32

04103 Leipzig

E-mail: gesc@medizin.uni-leipzig.de 